\title{
Inmate Rehabilitation Revisited: Using Goffman and Perrow to Explain Constraints on Transformational Technologies in Prison
}

\author{
J Forbes Farmer, Ph. D., Professor \\ Sociology Department, Franklin Pierce University, 40 University Drive, Rindge, \\ New Hampshire, USA \\ E-mail: Farmerjf@Franklinpierce.edu
}

Received: March 19, 2014 Accepted: April 22, 2014 Published: April 25, 2014

doi:10.5296/jsss.v1i2.5319 URL: http://dx.doi.org/10.5296/jsss.v1i2.5319

\begin{abstract}
Informed by the work of sociologists Erving Goffman and Charles Perrow, the author focuses on the perspective that prison inmates are human material that get exposed to transformational technologies (educational and medical). Some constraints (environment and resources) on these technologies are discussed in relation to rehabilitation and recidivism. The emphasis here is on the internal limits of prisons' ability to transform human behavior and attitude. This, however, is not intended to underestimate the external constraints which, in fact, get discussed throughout this paper. The author agrees with those who believe that the best rehabilitation design is structured around evidence-based programs that prepare inmates for reentry to, and full citizenship in, society.
\end{abstract}

Keywords: Rehabilitation, Recidivism, Medical model, Organizational theory, Offender reentry 


\section{Introduction}

One of the most significant social issues in America today is that about two million U.S. citizens are behind bars on a daily basis (Shannon \& Uggen, 2014, p. 42). The incarceration rate (750 per 100,000 people) is the highest rate of any free country (Petersilia, 2011, p. 26) and is the result of the mass incarceration (Garland, 2001) that began 40 years ago. The incarceration rate in Europe is estimated to be a sixth or a seventh the size of America's (Lageson, 2014, p. 144). This mass incarceration buildup in America that began in the 1970s was precipitated by the same conservative political posturing that, together with a critical liberalism, also ended the rehabilitative era of penal practice that was based on what was known as the "medical model." The medical rehabilitative technology, developed around 1930 (Allen, Latessa, \& Ponder, 2013, p. 49) was widely applied, with some controversy, until the mid-1970s when it was replaced with a more punitive, visceral, emotive (Goodman, 2012), reintegration-deterrent-incapacitation model of treatment (Phelps, 2011, p. 34) in a "warehouse prison" (Irwin, 2005). The consensus was that "nothing worked" in rehabilitating inmates (Seiter, 2014; Phelps, 2011). Almost thirty years after this consensus view, Garland (2001) wrote that the penal-welfare technologies are still is use. Cullen (2005), President of the American Society of Criminology, wrote that rehabilitation was "making a comeback," and others (Frampton, M., Lopez, I., \& Simon, J., 2008; Steen \& Brandy, 2007) claim that it is "back on the table."

Now, forty years after the abandonment of the rehabilitative ideal, Simon (2014) suggests that a California ruling (Brown v. Plata, 2011) signals an American return to the use of the medical rehabilitative model of treatment in prisons. Wacquant (2008) also pointed out that the major reduction of social services in disadvantaged neighborhoods has left prisons as a place of last resort for such rehabilitative social services as medical care, remedial education, drug treatment and counseling. Rossum and Rossum (2014) have even concluded that there is now evidence that rehabilitation did work after all, and could still work, although only if it is more structured around evidence-based, reentry programming (Clear, Cole, Reisig, \& Petrosino, 2012) and less on the old medical model (Alarid \& Reichel, 2013). This focus seems to have bipartisan support in the United States Congress (Colgan, 2007).

The aim of this essay is to offer an innovative approach to the traditional exercise in prison criticism, which, although always an acceptable and worthwhile enterprise, often gets stuck in its own inbreeding. The boldness, energy, life, imagination and enthusiasm running through the $18^{\text {th }}$ century work of Howard (1777) and Bentham (1962), then through Perrow (1958), Goffman (1961), Foucault (1977), Irwin (1980) and others leaves an indelible impression of prison and prison life. Thus, this paper begins with a comment on the usually cited prison goals: deterrence, punishment, incapacitation and rehabilitation. This leads to a brief history of the changes in correctional focus including the development of the rehabilitation concept. The concept of transformation is then developed. This term will be used interchangeably with rehabilitation throughout this essay. Transformation takes on a special meaning as it gets discussed in relation to the application of transformational technologies applied to human "material." The term "technology", appearing throughout this essay, refers to the general knowledge and means used to produce or alter a product of either 
individual material or human "material." The term "technique" is also used. This is a more specific term than "technology" and refers to either a method of performance or a skill which is characteristic of the corrections profession. A "technique" is part of a technology system.

The technology of transformation has received some prior sociological study. Mental institutions (Goffman, 1961) and hospitals (Perrow, 1958) have been studied from this traditional perspective and serve as the basis of this paper's theoretical orientation; that prisons, like mental institutions and hospitals, apply transformational (rehabilitation) technologies to their "material" - the inmates. It is then shown that transformation (rehabilitation) did not work. Some reasons why it did not succeed become the central focus of this work. Two transformational technologies (education and the medical model) are identified along with their techniques of application and the internal constraints on these technologies are explored. A typology of these constraints is presented along with the causes of the constraints. Some possible remedies are then offered along with predictions of their chance of success.

\section{Prison Goals and a Brief History of Rehabilitation}

The goals of imprisonment have continuously been debated. Some have argued for punishment (retribution), some for restitution (restorative justice), some for deterrence (specific and general), some for incapacitation (protection), and others have supported rehabilitation (Seiter, 2014). To understand the current reentry-punitive American prison philosophy it is useful to scan the shifts in correctional focus that have occurred over the past few hundred years in this country and abroad. An examination of these shifts gives insight to the influence of the political, economic and social external environment discussed by Simon (2014). For example, the 17th century English correctional system was firmly grounded in the idea of retribution by the state. Evidence of the predominance of vengeance is seen by the fact that politicians identified over 200 crimes for which an offender could be executed (Allen et al., 2013, p. 11). This system, at the time, had an impact on the American colonial correctional philosophy and later on the republic. Hanging, branding, flogging and use of stocks and pillory serve as examples of a shortage of forgiveness (Seiter, 2014).

These examples also point out how culture determines technology (Clear et al., 2012); the subject of a later section. But, there was a major change in philosophy in the 18th century during the Enlightenment. It was during this period that Cesare Beccaria, Voltaire, Jeremy Bentham, and John Howard wrote about crime, criminality, and penology. At about the same time Voltaire was writing in France to support human rights and challenge old ideas of justice and criminal responsibility, Beccaria, in Italy, published An Essay on Crimes and Punishments (1764) that almost immediately influenced penology. Among his contributions, the notion was that punishment should not provide social revenge, but should deter people from crime (Allen et al., 2013; Seiter, 2014).

In the late 18th and early 19th centuries, Bentham reformed the British criminal system by bringing about political equality (Allen et al, 2013) before the law and penal measures to control crime (Simon, 2014). Bentham's work and the resulting legislation, give evidence of the importance of the external political influence (Jayewardene \& Jaysuriya, 1981). Conrad 
(1981) argued that it is "incontestable" that Bentham was the first person to couple incapacitation and rehabilitation as goals for the criminal justice system. He argued, like Beccaria, that punishment, if appropriate to the crime, could be deterrent. To this end, Bentham's notion of punishment integrated incapacitation, reformation and intimidation (Simon, 2014). If an inmate committed a nonviolent crime (violent criminals were not considered), he could possibly be returned to society if he had been properly reformed and intimidated. This was a qualified rehabilitation and Bentham's solution to the crime problem. "Morals reformed - health preserved - industry invigorated - instruction diffused - public burdens lightened" (Bentham, 1962, p. 39).

This concept was based on the hedonistic principle that people will maximize pleasure and minimize pain (Allen et al., 2013; Seiter, 2014). It was this principle that lead to the rehabilitative ideal. If the state was going to incarcerate people, it had an obligation to transform them into citizens who would conform to society's standards. Transformation was an extremely authoritarian and utilitarian idea which, to be carried out, depended on some technology for overpowering the inmate. Goffman (1961) wrote that some institutions say they 'rehabilitate' by "resetting the inmate's self-regulating mechanisms before release" ( $\mathrm{p}$. 71). There is a double meaning to "discipline" implied here; negative discipline to deter and positive discipline to rehabilitate. This concept gets developed later in the section on transformational theory.

Howard, Beccaria, Bentham and other Enlightenment thinkers, like William Penn, influenced correctional philosophy in America. It was Penn actually who brought the concept of humanitarian treatment of offenders over to America from England (Allen et al., 2013; DeLisi \& Conis, 2013; Seiter, 2014). Quaker rules in Pennsylvania ultimately brought about, in 1790, the establishment of a section of the Walnut Street Jail to be used as a place where inmates, in solitary confinement, could reflect upon their crimes and have an opportunity for "penitence (sorrow and shame for their wrongs) and repentance (willingness to change their ways)" (Clear et al., 2012, p. 16). It was hoped, of course, that this custodial confinement would "morally reform" (Cullen \& Jonson, 2012, p. 28) the inmate and prevent his committing more crime upon release. This jail was the first prison to be used exclusively for the purpose of correction, as opposed to punishment, (Allen et al., 2013). Isolation was used to bring about this reformation, but it was soon replaced with work and religious instruction. The goal was what Goffman (1961) called the alteration of the "self-regulating inner tendencies of the inmate" (p. 24). From the Walnut Street Jail grew many similar prisons which became known as the Pennsylvania system (Seiter, 2014). There were, however, some systems that departed from this model.

It was at this time that American penologists met and adopted a combination of ideas based on the writings of Alexander Maconochie from England and Walter Crofton from Ireland. The penologists adopted the indeterminate sentence (Clear et al., 2012) which replaced the fixed sentence. The inmate would be released when it was determined that he was penitent and was prepared for a crimeless life and a legitimate job. At the first meeting, in 1870, of the National Prison Association it was declared that "reformation, not vindictive suffering should be the purpose of penal treatment of prisoners" (Conrad, 1981, p. 9). The significance of 
reformation became particularly vivid from this date on, as social scientists in the areas of psychology, biology and sociology began amassing theories that tried to explain, or identify the cause of, human behavior. A philosophy of penology was developed which was "based on the concept that criminal behavior was caused by identifiable and changeable forces" (Irwin, 1981, p. 39). This led to the notion that crime could be reduced by treating the criminality in the criminal. Thus developed the rehabilitative ideal supported by psychological theories (Phelps, 2011) and methods from the sciences. This penal goal came to the forefront in the 1950s when America wanted to become involved in bettering the human conditions.

In 1876, the Elmira Youth Reformatory was built in New York to embody these principles (Clear et al., 2012, p. 19) and eventually prisons across the United States adopted the rehabilitative plan (Allen et al., 2013). "In the reformed, rehabilitative prison, the central principle of the institution is 'treatment' designed to 'cure' the inmate of his criminality, to rehabilitate him 'from his fallen state", (Wright, 1973, p. 42). Custody and rehabilitation were coequal goals. Some researchers, however, cast doubt on these objectives. They believed that the 19th century in America was a significant period for the development of the notion of "transformation of the criminal into the bourgeois image of how 'propertyless' 'should be" (Melossi \& Pavarini, 1981, p. 124). By the end of the 19th (Alarid \& Reichel, 2013) and the early 29th century the reform movement declined (Clear et al., 2012). Now in the 21 st century the emphasis in the criminal justice system seems to be that custodial and rehabilitative goals can be carried out at the same time. But Goffman (1961), over 50 years ago had warned that prisons could not simultaneously serve as "storage drums for inmates" ( $\mathrm{p}$. 74) and as reform agents. Today, the hope still lingers that some intentional intervention (rehabilitative technology), or transformational process can be introduced which might better affect recidivism, especially efforts towards reentry (Phelps, 2011).

\section{Transformational Theory: Mental Institutions and Hospitals}

The notion that total institutions could be an active transformational agent analogous to an industrial manufacturer has received some attention in the sociological literature. Goffman (1961) wrote that "as material upon which to work, people can take on somewhat the same characteristics as inanimate objects" (p. 74). He also referred to the mental patient as being like a processed article which carries records with it showing what has been done to it and by whom. Like Goffman, Perrow (1958) analyzed organizations "in terms of the work performed on the basic material which is to be altered" (p. 913). He viewed hospitals as "systems which utilize energy in a patterned, directed effort to alter the condition of basic materials in a predetermined manner" (Perrow, 1958, p. 913). He further believed that this goal was determined by American culture. "It is the cultural system which sets legitimate goals" (Perrow, 1958, p. 912).

Perrow (1958) showed how, in the history of mental hospitals, the search for techniques of cure and care was dictated by cultural beliefs. Mental patients in colonial America were locked up in private, unventilated and unheated houses because the patients were viewed by the Puritans as having given in to a beast-like nature and were, thus, immune from cold. But this type of housing changed in the 19th century due to industrialization and overcrowded 
cities. Institutional care arose at this time, but techniques for curing the insane were still based on the belief that insanity was caused by brain disease. Various medical treatments, such as bleeding and shock treatment, were applied that might seem cruel, but that were justified by the belief that the insane were insensitive to their surroundings and thus immune from pain (Perrow, 1958).

Perrow (1958) provided many other examples of how technology follows from culture. He showed how "moral" treatment developed during the French Revolution when individual rights were being won and the concept of "personality-based-on-experience" was taking hold. The rise of this new treatment method was also explained by new theories of insanity which were based upon physiological knowledge connecting human behavior to brain function. And brain function depended upon how the individual experienced his external environment. It was thus believed that a person could be changed if his environment was changed (Perrow, 1958). And this required a technology, which, for the purpose of this essay, is defined as general knowledge, means or set of techniques, used to alter people in an anticipated way. This requires the expectation that technology when accurately employed will lead to alteration or change. It also requires a mechanism for feedback.

\section{Transformational Theory: Prisons}

The concept provided by sociologists Erving Goffman (1961) and Charles Perrow (1958) of using transformational technologies, and their techniques, to alter the behavior of mental patients can also be applied to rehabilitative technologies in prison. Goffman (1961, p. 74) referred to the processing of mental patients as if they were industrial material. In the same sense, then, the prison can be considered a formal organization that can intentionally and instrumentally design and shape a product (inmates) ready to be sent back to the community. And although Perrow (1958), like Goffman, refers to the hospital setting, the transition to prison analysis seems consistent. Prisons, like hospitals, can be viewed as "systems which utilize energy in a patterned, directed effort to alter the condition of basic materials in a predetermined manner" (Perrow, 1958, p. 913).

Accordingly, the alteration of human "material" is still one of the contemporary goals of American prison. This includes training for marketable skills, anger management, making better choices, reduced drug dependency, nutritional education (Allen et al., 2013), reduction in mental illness and improvement in literacy skills (Alarid \& Reichel, 2013). As seen in an earlier section of this essay, rehabilitation has not always been a prison goal. It is certainly not the main function of the contemporary prison. Just as the culture determined the technology in the mental hospital, it still determines the goals and technology in prison. Today's cultural priority is individualism and self-responsibility. For penal philosophy, this means custody is more important than rehabilitation. Spending money to rehabilitate is not a priority goal. The cultural goals determine the technology which, in turn, determine the organizational structure necessary to implement these goals (Perrow, 1958). There is interdependence, then, between the cultural system, the technology and the social structure in prison which affects the style and success of the transformational (rehabilitative) process. Prisons "deal with human beings, processing them and manipulating them" (Jayewardene \& Jaysuriya, 1981, p. 149). A similar 
description of this process comes from Cressey (1975) who wrote that treatment "is likely to be that of a 'stream of action' in which clients or patients, like raw materials, pass through the prison and have various rehabilitation operations performed on them, each according to his needs" (Irwin, 1981, p. 129).

A necessary ingredient in these rehabilitative operations is some form of discipline. It has been applied through various behavioristic designs to both punish and reward inmate behavior. "Just as treated steel is plunged into a chemical bath, relatively simple manipulation of the punishment-reward system of this custodial prison is expected to convert the inmate into the desired product" (Johnson, 1978, p. 443). This was the utilitarian idea espoused by Beccaria's hedonistic explanation of crime. Punishment was meant to serve as a warning and deterrent to criminal behavior (Allen et al., 2013; DeLisi \& Conis, 2013). This included the reforming of those who had already committed crimes. It has been said that the "art of punishing, then, must rest on a whole technology of representation" (Foucault, 1977, p. 104). This means that, to serve as a deterrent, the punishment had to be severe enough to be meaningful and to force the individual into concluding that pleasure would best be maximized by not committing criminal acts and by complying to social expectations (DeLisi $\&$ Conis, 2013). The utilitarian nature of this technique was found by Foucault to have roots in the late 18th century in the form of making soldiers. Through a process of construction, mastering, correcting and molding one "has 'got rid of the peasant' and given him the air of a soldier" (Foucault, 1977, p. 135). Similar to Goffman's (1961) explanation of the reconstruction of "self," the body was made more obedient and useful by exposure to "a machinery of power that explores it, breaks it down and rearranges it" (Foucault, 1977, p. 138).

Discipline not only serves the prison-as-deterrent model, it is also needed for rehabilitation and can, in this sense, be regarded as positive discipline. Both kinds of discipline, positive and negative, are necessary if prison is to serve the functions of prevention (deterrence) and reform. And both types need technologies if they are to be applied. The technique of discipline included meticulous methods that Foucault (1977) called "a political anatomy of detail" (p. 139) which "makes individuals; it is the specific technique of power that regards individuals both as objects and instruments of its exercise" (Foucault, 1977, p. 170). The rehabilitative techniques used were constant observation and the normalizing or correcting of the inmate's judgment. This was a calculated manipulation of the person's attitude and behavior. It is to this and other rehabilitative (transformational) techniques that attention now gets turned.

\section{Transformational Technologies}

The assumptions and rationale for the rehabilitative ideal included the conclusion that criminality has antecedent causes which could be identified and that the criminal could be altered by applying technologies (Allen et al., 2013; Clear et al., 2012). A technology, as stated in the introduction, is the knowledge and means used to produce or alter a human product. The transformational ideal included two available alternative rehabilitative devices or "technologies." The first technology was education: the process of instructing, training and 
teaching of skills and information. Education, as a technology, was viewed in the broadest sense. It was, and still is, identified as the most important factor in increasing the likelihood of a prisoner's rehabilitation (Allen et al., 2013; Alarid, \& Reichel, 2013; Batiuk, Lahm, McKeever, Wilcox, \& Wilcox, 2005; Miller, 2014). There are several techniques used in prison to apply this technology. These techniques include, but are not limited to, vocational training, classroom schooling, committee work, inmate self-government and participatory management, and community corrections.

The second technology was the medical model: the process of determining the personality and character traits of the inmate, assuming the offender to be ill, having the causes diagnosed and then cured through some form of treatment (Cullen \& Jonson, 2012; Seiter, 2014). The techniques used in prison to apply the medical model included, but were not limited to the indeterminate sentence, classification, therapy, graded security levels, mortification, discipline, and isolation. The rationale for these techniques follows in two sections: educational techniques and medical techniques.

\subsection{Educational Techniques}

Vocational training was, and is, meant to provide marketable skills and positive attitudes towards work and self-support. It is also viewed as an activity intended to increase the offenders' connectedness to society (Cullen \& Jonson, 2012). Through the prison industries or some government funded training program (Miller, 2014), the inmate can learn proper work habits and earn the pride associated with the completion of some task, project or assignment. The training programs and industries include the techniques of auto mechanics, welding, carpentry, printing, plumbing, cooking and computer repair (Alarid \& Reichel, 2013). These can be coupled with education programs and degree opportunities. Some of the educational programs culminate with a high school diploma. College courses and programs are also available in many prisons (Alarid \& Reichel, 2013) although college courses have come under attack (Clear et al., 2012). Many inmates have also educated themselves through the availability of prison library holdings. Another technique is the committee work and organizational affiliations available to the inmate. Some, such as the Seven Steps addiction program, are self-help organizations. There are also a variety of religious and political groups. These offer the inmate an opportunity for involvement, self-expression, emotional support and friendship (Goffman, 1961).

While not a "prison" technique, community corrections was, and to a limited extent still is, another model designed to rehabilitate. The rationale here was, to integrate the inmate into a more realistic environment where he could maintain community and family ties while abiding by certain conditions (DeLisi \& Conis, 2013). The basic technique is to put the inmate in contact with the institutions that are responsible for assuring the development of good work habits and marketable skills. Community corrections is also less punitive than prison and, thereby, offers fewer restrictions of civil liberties. There is some evidence that this approach failed to deliver and that it has been remodeled and operating under "justice reinvestment" (Clear et al., 2012, p. 106).

Inmate self-governance and participatory management was a progressive idea in the 1960s 
and 1970s, but the concept is not utilized much anymore except in other countries like Bolivia, where the administration is more relaxed and there are no rehabilitative services (Skarbek, 2010). It is a method of involving inmates in decisions and negotiating problems with them. It is a form of sharing power, "but not abdicating authority to them" (Stinchcomb, 2011, p. 161). Fifty years ago it was supposed to have as its goal the development of personal growth, self-actualization and a sense of self-worth. Some disagreed with this. Goffman (1961), for example, saw participatory management as a tool used by the prison administration to foster less loyalty to the "counter-mores" and more loyalty to the staff-defined rehabilitative ideal. Some scholars thought of this rehabilitative technique as a way of countering the negative effects of mortification. Jaywardene and Jaysuriya (1981) saw it as calling "for the modification of the role of the inmate by endowing it with greater dignity, power and significance" (p. 8). Regardless of its goal, participatory management was taught through role modeling, courses, workshops and seminars and was thus part of the education technology.

\subsection{Medical Model Techniques}

The predominate technique used under the old medical model was the indeterminate sentence. It was supposed to motivate the inmate, since the inmate was told he could speed up his release through constructive prison work and good behavior (Seiter, 2014). It also was said to reflect the needs of the offender and not the gravity of the crime (Rossum \& Rossum, 2014) because the length of incarceration was partly determined by the inmate's progress towards rehabilitation (Cullen \& Jonson, 2012). Other supporters of the indeterminate sentence, such as Karl Menninger, argued that it allowed the prison staff to concentrate on the treatment (Irwin, 1980). The level of cure would be determined by the parole boards that were empowered to judge, through some technique, the sufficiency of rehabilitation transformation as they made release decisions (Seiter, 2014).

Another technique was, and continues to be, classification. This involves administrative techniques which attempt to split the inmate population into different manageable security groups for prison and housing assignments (external classification) and to identify inmate needs for individual programs (internal classification) (Allen et al., 2013). Classification includes complex and elaborate diagnostic techniques such as testing, evaluating and interviewing, which result in an individualized therapeutic plan. Therapy (individual, group and milieu), gives the inmates the opportunity to develop insights into their personalities and life circumstances which might facilitate attitudinal and behavioral change. Conrad (1981) believed that the use of classification epitomized "everything we were doing in the name of the medical model" (p. 10). Through another technique, the security-level system, the inmates move to prisons or housing units with fewer restrictions and more freedom depending on the inmates' positive social adjustment and personally constructive behavior. It is assumed there is some technique for judging this. The security-level system, while designed primarily for custodial and supervisory reasons (DeLisi \& Conis, 2013) also allows for participation in activities designed to enable personal growth and development. Obviously, participatory management, graded security levels, vocational training and the other transformational techniques just cited are blended with the seemingly ageless techniques of mortification, 
discipline and isolation.

As to mortification, Goffman (1961) provided convincing documentation of the degradation and debasement which many see as an intentional method used to force the inmate into submission. The process involves "humiliations and profanations of self" (Goffman, 1961, p. 14). "Newcomers are stripped of personal belongings and given a uniform, rulebook, medical examination, and shower" (Clear et al., 2012, p. 178). The rationale is that once the old self is broken down, a new psychology can be shaped, one that holds to conventional norms and beliefs. "This process is done, in part, to underscore the fact that the inmates are no longer free citizens" (Clear, 2012, p. 179). Discipline as it has previously been argued, has the same rationale. It has the function of reducing gaps between acceptable and non-acceptable behavior. "It must therefore be essentially corrective" (Foucault, 1977, p. 179). The principle of isolation also has reformation as a goal. The idea for this came from the Quaker notion of repentance discussed earlier. It involves a recoding of the individual's physical and moral existence. The technique was simply the removal of the inmate "from the external world, from everything that motivated the offense, from the complicities that facilitated it" (Foucault, 1977, p. 236).

Having identified two technologies (education and the medical model), and several transformational techniques and, having provided rationales for them, it is now necessary to state that these alternate techniques have only had limited success in bringing about the desired result - transformed human "material." The subject of the remainder of this essay is to give proof to this argument and to discuss constraints in the prison systems which work against rehabilitative efforts.

\section{The Failure of Rehabilitation}

The efforts and changes made by Bentham, Beccaria, Howard, Penn, Maconochie and Crofton, which have been previously discussed, spawned the development of these various rehabilitative techniques. The commentary used to be that rehabilitation rarely worked. Prison technologies, when applied through the techniques, did not successfully rehabilitate (transform) inmates. However, penologists and prison administrators continue to provide empirical evidence, in the form of recidivism statistics, that the transformational efforts succeed (Aos, Miller \& Drake, 2006; DeLisi \& Conis, 2013). But 40 years ago, the Martinson (1974) report provided the real death-knell to the rehabilitationists. His work publicized the results of a survey of 231 treatment reports in New York which concluded that treatment had not worked. He even "called rehabilitation a myth (a view that he later renounced, just before his death)" (Allen et al, 1981, p. 406), and contended:

Except for castration, there is no startling evidence of success. There is no method for reversing the powerful tendency of offenders to persist in criminal activity. The tendency may be reduced somewhat by a given method but percentage differences are small and the costs of achieving these small reductions may be high. In the face of such facts it seems absurd to insist that the official aim of the post-adjudicatory process is to "rehabilitate" the offender. Worse, such a demand may tempt prison officials to achieve the impossible (Martinson, 1974, p. 22). 
The Martinson report returned the same general verdict as Wilkins (1969) who also reviewed treatment and recidivism. There were many prison administrators who held to the rehabilitative ideal, however. Serril (1975) and Colgan (2007, p. 110) pointed out that 63 percent of them believed rehabilitation was effective even though Hawkins (1976) believed there was not enough evidence to reach this conclusion. According to Irwin (1980), inmates watched treatment participants returning to prison for additional offenses or parole violations and were convinced these rehabilitation programs did not work. Bailey (1966) found that "little of the rehabilitation work being done should be dignified by the term "treatment" ( $\mathrm{p}$. 157). He studied 100 different projects.

Roughly one-half of the outcome reports evaluated concluded considerable improvement in the treatment group. Almost one-fourth of the reports concluded either harmful results or "no change." These results, based upon the reported findings themselves, raise some serious questions regarding the efficacy of correctional treatment (Bailey, 1966, p. 157).

Most scholars doubted that the transformational rehabilitation process succeeded in its aim of preparing the inmate for life after release. Goffman (1961) said that life on the outside could never be the same as before incarceration simply because of the prison stigma. And Conrad (1981) said that "the system blocks the offender at every turn" (p. 20). Maybe this explains the cautious optimism today that has moved from "nothing works" to "what works?" (DeLisi \& Conis, 2013, p. 320).

There are characteristics found within the prison that negatively influence rehabilitation that are at the root of this skepticism. The forthcoming analysis of these internal factors reveals that prisons not only work against themselves in regards to rehabilitation, but that there are structural impediments to the development of programs that could achieve this objective. Goffman (1961) once said that one can understand the issues of a total institution by looking at what goes on in the inside, and it is to the internal constraints that this discussion now turns.

\section{Constraints and Rehabilitation}

It has just been argued that transformational technologies rarely worked to bring about rehabilitation. Critics like Hawkins (1976) claimed that these technologies successfully provided "an illegitimate extension of power over individuals in order to achieve indoctrination of white Anglo-Saxon middle-class values" (p. 23). But even for those who are not abolitionists like Hawkins (Irwin, 1980, p. 231), rehabilitation mostly did not work. The explanation for its limited success is found in the study of internal constraints, which includes a conceptualization of how these constraints work to prevent the actualization of the transformation process. These constraints can be grouped into the following typology: Type A (Prison Environmental Contraints) and Type B (Resource Constraints).

\subsection{Type A (Prison Environmental Constraints)}

These are the attitudes and conditions which determine the prison atmosphere and situational reality. They represent the values of the outside society, the prison administration and/or the inmate. They relate to the general concept of communication and interaction between the 
staff and inmates and between inmates or inmate groups. They are the basis around which prison activity is organized. These constraints include (1) the omnipresence of prison's control function, (2) inmate discontent with over-crowding and sentencing disparity, (3) the prison subculture including race and ethnic groupings, age and crime differences, geographical groupings and the sub rosa economy, (4) prison violence and overcrowding, (5) the process of mortification and (6) the lack of support for inmates to participate in self-government and in participatory management.

Prison wardens undoubtedly ask themselves "what results am I being paid to achieve?" If the answer is control and custody, then they are quite successful as evidenced by the mass incarceration described by Cullen \& Jonson (2012), Phelps (2011), Wacquant (2008) and Garland (2001). But the omnipresence of the prison's control function means that the correctional officers' (CO's) official role is custody and supervision. This Type A constraint results in a highly supervised mass movement of inmates through the prison routines (Goffman, 1961). This mass control allows for little individualism to develop and there are limited legitimate opportunities for the inmate to increase his status on the inside. The COs, fearing that they may lose control, keep a tight rein on inmate activities (Clear et al., 2012). Some COs are suspicious of the "population" rather than supportive of rehabilitation efforts. Since there is a lack of aggressive planning for rehabilitation, there are competing operational goals which lead to confusion over desired staff-inmate boundary relationships (Clear, 2012). While the COs' official role is custody and supervision, they are also expected to provide some levels of therapeutic understanding and facilitating (Allen et al., 2013). To clarify this confusion would take, on the micro level, a redefinition of the COs' role and job description. This would be easy enough to accomplish if COs were willing to cooperate and prison administrations gave their organizational commitment (Lambert, Hogan, Barton, Jiang, \& Baker, 2008). The technology is certainly available to teach them. Of greater importance, however, is the need to get rehabilitation returned as a coequal goal along with custody. Right now that is only being discussed. The social and political climate in the United States is not conductive to making the necessary legislative changes. Democrats and Republicans are too ideologically separated, especially with the current influence of the far-right-wing conservative Tea Party. With a few exceptions like the 2014 Health Care Act, goals are conservative ones; reduce taxes, reduce government involvement in local issues, support individualism and self-responsibility.

This political reality supports another one of prisons' rehabilitative techniques, the indeterminate sentence. About 30 states still use some form of the indeterminate sentence (Cullen \& Jonson, 2012, p. 33), but penology will probably never fully return to this. One particular constraint that works against the effectiveness of this technology is the attitude the prison population and many academics have towards the indeterminate sentence. The inmates used to see the indeterminate sentence as being manipulative, confusing, hypocritical, and discriminatory (Irwin, 1980). Its success implies a kind of self-motivation usually not possible in prison (Prettyman, 1981). Most importantly, it requires that other techniques be applied to foster motivation and improvement of the inmate's psychological condition. These techniques are constrained. It was, and is, widely agreed that this sentence gives too much 
authority to a parole board which is, at least used to be, poorly trained to make intelligent decisions (Prettyman, 1981). In any event, inmates saw this technique as an unfair game to be played. They did not know the length of their sentence and they found their fate in the unpredictability (Bohm, 2006) and arbitrariness of the board that "added their two cents" (Cullen \& Jonson, 2012, p. 62). The inmates become proficient at pretending to be corrected (Allen et al, 1981). The indeterminate sentence was eventually replaced with forms of fixed sentencing. Foucault (1977) wrote that "punishment can function only if it comes to a known end" (p. 107). The effectiveness of the indeterminate sentence as a transformational technique, then, was severely restrained by the inmate's attitude and behavioral responses to it.

Another Type A constraint on the rehabilitative techniques are the various prison subcultures. Prisons, like other organizations, are "social systems which are populated by individuals who come with norms, values, and expectations, and with a need to develop an understanding of their world around them" (Pfeffer, 1981, p. 181). One finds that inmates in today's prison organize themselves into some type of social system (Allen et al., 2013). Typically, the groups are racial, geographic or based on personality type (Seiter, 2014). These groups provide the inmate with support, goods, and services, protection and power (Alarid \& Reichel, 2013). Through these groups the inmate can obtain illegal and contraband items such as sex or drugs (Seiter, 2014). Both of these items are in demand and available. Drugs get smuggled in the prison and become a means of making money and raising one's status. But an underground market is needed to sell and purchase them. The availability of the sub rosa economy (Clear et al., 2012) undermines the "rehabilitative" economy. The honest income earned through hard work loses its meaning and purchasing power when illegal wealth and power is allowed to accumulate.

In so far as the prison subcultures control the inmates' behavior in a negative sense, as it does in the sub rosa economy, the subcultures restrain the other rehabilitative techniques as well. One typical subcultural grouping in today's prison is division along social or ethnic lines (Alarid \& Reichel, 2013). White, black and Chicano inmates do not mix in informal prisoner groups, and many form groups for power and protection (Allen, 2013). All this leads to defacto segregation which creates tension when inmates are classified and housed by crimes committed or by personality type (Alarid \& Reichel, 2013). The tension this brings to a graduated security-level technique makes the implementation of these graduated security-level techniques complicated and difficult (Allen, 2013). There is little hope that this situation can change, especially in maximum security prisons. Informal groupings are natural and do, in a positive way, provide the inmate with pride and support. This racial and ethnic pride, however, also substitutes for the pride of individual achievement. And group leaders become attractive substitutes for more appropriate, socially acceptable role models such as successful professionals. There are some ways this constraint could be turned into a force that supported the techniques. It might be through the creation of smaller prisons that would allow different race, ethnic, geographic and age groups to interact in a less threatening environment where it would be to everyone's benefit to get along.

Another Type A constraint, the violent and overcrowded conditions, remains a threat to rehabilitative efforts (Clear, 2012). Today, as back in the rehabilitation era, the "hero" in the 
maximum security men's prison is the man who is tough. According to Irwin (1980), this means "first, being able to take care of oneself in the prison world, where people will attack others with little or no provocation. Second, it means having the guts to take from the weak" (Irwin, 1980, p. 193). It is to demonstrate the aggressor's superior strength and to mark the victim as weaker (Toch, 1977). To pursue safety in this environment, the threatened inmates seek out safe areas and identify areas to avoid. When asked what place he saw particularly dangerous, one inmate answered "over in the school is a big thing because you are pretty much away from the officers. It is like the metal shop where you get behind some of these little work areas" (Toch, 1977, p. 173). In addition to finding safety by selecting one's physical environment, inmates seek protection through their selection of social environments. They make contacts and chose relationships with those they think they can trust.

Inmates are most likely to trust others of the same race or ethnic group if they have no other information to go on. The atmosphere of violence is compounded by the fact that prisons are overcrowded (DeLisi \& Conis, 2013; Seiter, 2014). There are less safe places to be found because there are more inmates to fill them. Additionally, the limited number of COs are spread around more thinly (DeLisi \& Conis, 2013). This not only results in more custodial action from the COs, such as using forced segregation to maintain discipline and protect the weak inmates from attack (Fox, 1983), but it means a tightening up on freedoms such as recreational opportunities and prison industries. Idleness increases, and inmates fight among themselves. When these overcrowding conditions exist, the prison staff, "in order to maintain even a semblance of control within prisons, has to compromise standards and rules of behavior for the sake of safety, and inmates perceive this and react to it" (Allen et al., 1981, p. 403).

It seems obvious that these violent and overcrowded conditions act as impediments to the rehabilitative techniques and short of tearing down the old prisons and replacing them with smaller, more comfortable prisons, there seems to be little hope of change. The number of inmates has been increasing since the 1970s when the public's fear of crime increased and the "tough on crime" punishment ideology was reactivated (Seiter, 2014). Average sentences have also been getting longer (Seiter, 2014) and inmates have been serving longer determinate and mandatory terms (Bohm, 2006; Phelps, 2011) since the sentencing discretion shifted from the judge to the prosecutor (Clear et al., 2012). Another reason why change is unlikely is because the American public believes the inmate should not live in conditions that are better than the worst conditions found in the noncriminal population (Hawkins, 1976).

Another Type A constraint was, and continues to be, a lack of support for participatory management and inmate self-government. This was an experimental and liberal technique used in the height of the rehabilitative era (1960-1970). Early efforts to employ this educational technique failed due to the prison's failure to offer enough protections and controls. Some powerful inmates used the process to further their own ends (Stinchcomb, 2011). Additionally, the less powerful inmates did not support this as they usually found only a small margin of self-determination and command over their world anyway (Goffman, 1961). But, "If prison is to rehabilitate, among the things it must help to do is to buttress the individual's decision-making facility; it must help to mature the individual, to make him 
self-reliant" (Leopold, 1969, p. 31). Participatory management, were it more available in prison, would provide the inmates (and the COs) opportunities to discuss prison goals and objectives and to make decisions. The inmate would have some control in the management of the prison. He could even run certain aspects of the prison and be evaluated on his performance. This would help him develop a sense of self-worth and a feeling of importance and respect. It would elicit adult behavior and make prison life more meaningful because one's capacities would be challenged to the fullest. In the 1960s and 1970s there had been a whole range of experiments with this model involving different degrees and levels of participation (Baunach, 1981).

Despite this experimentation, there is still a lack of opportunities. One simply does not hear about this anymore. This lack of support for participatory management is based on the administration belief that their control would be compromised. So, the organizational structure of the personnel clearly identifies the custodial staff as having the final word and "treatment" personnel are relegated to secondary positions (Seiter, 2014). The organizational separation of these functions (control and treatment) means that "Most COs have nothing to do but $\mathrm{CO}$; they do not 'use' inmates productively any more than they themselves are used productively by prison managers. COs manage and are managed in organizations where management is an end, not a means" (Cressey, 1975, p. 79). In the past, inmates found little opportunity for sharing in discussions concerning prison goals and objectives. It seems better today as inmates meet with the treatment staff a few times a year to review the inmates' progress (Seiter, 2014). There are two hopes for replacing the traditional oppositional character of staff-inmate relationships with a softened and more humanistic-interactive system. One is the continued application of the decentralized, Unit Management, prison-management model (Farmer, 2012) that serves both a control and rehabilitative function. The other hope is in the hiring of staff who support rehabilitation (Lambert et al., 2008).

The technique of mortification has been listed as a "rehabilitative" tool particularly successful in serving the control function in prison (Clear, 2012). It has been described as a process involving degradation, debasement, humiliation and profanation of the self (Goffman, 1961). But while it serves this function well, the mortification process acts as a constraint on the educational and medical technologies and does not work to reduce recidivism (Cullen \& Jonson, 2012). It impedes the success of all techniques such as vocational training and therapy that attempt to improve the inmates' self-image and confidence. But, prisons today are far less "mortifying" than they were when society was more interested in retribution, and there have been enough court cases won to protect the inmate population from cruel and unusual punishment and inhumane treatment. Prison administrations are far more conscious of law suits and make considerable effort to protect themselves. Most training programs for COs emphasize the need to be fair with the inmates as a way of limiting the atmosphere of tension, hostility and oppression (Seiter, 2014).

The final Type A environmental constraint is the manner in which inmates adjust to prison life. Neither the mortification processes (Clear, 2012) nor the treatment processes "seem to have a lasting effect, partly because of the availability of secondary adjustments, the presence 
of counter-mores, and the tendency for inmates to combine all strategies and play it cool" (Goffman, 1961, p. 71). These methods of adaptation include: (1) withdrawal from everything except immediate events going on around the inmates' personal space, (Irwin, 1980), (2) taking the intransigent line of challenging everything the prison stands for and by refusing to cooperate with the staff, (3) maintaining a contented existence with the resource they have been able to take advantage of or "glean" (Irwin, 1980, p. 16) and (4) converting one's thinking to that of the official prison philosophy so that one tries to be the ideal, enthusiastic inmate (Goffman, 1961). These adjustments and alterations are necessary to help reduce tension and make their life easier (Alarid \& Reichel, 2013). The inmates come into the prison having already acquired a style of life. When they enter prison, they find a different set of social conditions which demand a different style of life and they adjust to an inmate code that directs their behavior (Alarid \& Reichel, 2013). The adjustments are accomplished through boundary testing designed to ascertain similarities and differences between prison and life on the outside. When defensive adjustments are made "it is difficult or impossible for some individuals to participate in treatment-oriented group practices" (Irwin, 1980, p. 36).

As long as the prison environment is characterized by these Type A constraints it will be very difficult, if not impossible, for transformational efforts to have any significant effect. The environmental conditions negatively influence all the techniques intended to rehabilitate. Many of the ways this happens has been discussed. The most significant environmental condition is that the rehabilitative and educational staffs have difficulty in reaching their goals in prisons where the most important mission is custody (Clear et al., 2012). This is explained in the next section on Type B constraints.

\subsection{Type B (Resource Constraints)}

This type of constraint includes the lack of technological materials and catalysts; those elements that are needed to make the transformation process happen. Some of the constraints are (1) the lack of trained staff, (2) the prison rules, living conditions, and routines that lack resemblance to the straight world outside, (3) the shortage of contemporary vocational equipment and opportunities, (4) the reduction of rehabilitation funds and (5) the inmate's lack of influential connections to the outside community.

If COs are to assist in the application of the transformational technologies they have to exhibit listening and supporting skills (Seiter, 2014). They have to be able to show empathy and give the inmate respect; not respect for the criminal behavior, but respect for the inmate as a human being (Seiter, 2014). Presently there is a mutual lack of respect between inmates and COs which hinders communication and the willingness to listen. This is going to require a change in thinking and a change in CO recruitment (Lambert et al., 2008) and training. Therapeutic skills are easy enough to teach, but the difficulty would be in training the CO to behave in both custodial and rehabilitative ways at the same time; to be able to adjust into either of these modes at will. Today, many COs enjoy this challenge, but there are still some who complain and are at odds with this mission (Seiter, 2014). The COs clearly have to incorporate more of the treatment staff's philosophy and think of the inmates as "material" having potential (Alarid \& Reichel, 2013). They would also have to start being rewarded for 
their listening and communicating with inmates. This, in turn, could result in more staff commitment to the prison organization (Lambert et al., 2008). Right now, they are only trained and rewarded for their control behavior (Clear et al., 2012), and since this pits them against the inmates who are also looking for control, a struggle for control exists and this reinforces a lack of communication (Perrow, 1958).

Due to the low pay, it is not easy to recruit the best educated COs (Alarid \& Reichel, 2013). Thus, some COs lack the rehabilitative skills and this affects all available technologies since they all involve communication in their application. It continues to be unrealistic to expect the rehabilitative services to work when the inmates and their most constant supervisor cannot relate. The fact that COs come from different subcultures than inmates leads to a lack of understanding of religious beliefs and ethnic values. COs also tend to be young, white males and from blue collar and uneducated backgrounds. Most of them, however are high school graduates or have their general education degree (GED) (Alarid \& Reichel, 2013). Those more poorly educated can lack self-confidence and self-respect. If this is coupled with the prison's lack of respect for the COs then the chances are even greater that respect for the inmate is prohibited. The CO's lack of support for inmates as the inmates struggle with their sentence continues to put considerable constraint on the technology.

Also requiring trained communication and interpersonal skills are the classification techniques and therapy programs (Alarid \& Reichel, 2013). The diagnostic techniques, which are part of this technology, require skilled people who can interview the inmate, articulate a treatment plan and communicate this process to the inmate. Part of this treatment plan could be some type of counseling; either group, individual or milieu. Previously it had been found, however, that only about half of these programs worked (DeLisi \& Conis, 2013, p. 220). The reason for this may have been in the quality of the counseling which was often very poor. The group sessions were frequently run by staff people with no formal training in psychology (Irwin, 1980). Today, with the advances in the field of psychological testing and risk-need-responsibility (RNR) assessment models (Petersilia, 2011; Phelps, 2012), it is easy to appreciate the complexity of contemporary classification procedures and decisions. Some programs have been effective, especially cognitive-behavioral ones (DeLisi \& Conis, 2013). However, the technology is only as effective as the people who apply it and the motivation of the inmates it is applied to (Cullen \& Jonson, 2012). There is evidence that the custodial and treatment staff, if properly trained, can be effective in the therapeutic process (Cullen \& Jonson, 2012; DeLisi \& Conis, 2013).

The rehabilitative hope is that the prison can improve the likelihood of inmates' success after they are released (Seiter, 2014). This follows from a notion of rehabilitation which would include the idea that the inmates should be prepared for citizenship and participation in the social institutions (DeLisi \& Conis, 2013). Unfortunately, life on the inside bears little resemblance to life outside and offers few citizenship opportunities. This constraint is partly caused by the prison administrations' failure to accept this citizenship as a goal. The concept must first be operationalized. That is, how will the prison administration and the inmate know when citizenship is being practiced? A general definition of the term would embrace the concept of responsible membership in a community. Responsibility is made evident by one's 
participation in the duties required to sustain the life and existence of the community. Outside the prison world this means voting, paying taxes, serving on committees and not being dependent on the government for basic needs. Welfare and family support might be acceptable for a while, but illegal sources of income should definitely be avoided.

To train the inmate so that he is an educated and responsible voter or an effective committee participant or an independent provider, it is necessary to make rewards and opportunities available. These are quite limited in prison, however (Clear, 2012). The rewards they do have include visitation privileges, recreation time, the number and length of phone calls, the amount of money that could be spent in the prison store and work assignments. These are necessary antecedents for the desired inmate behavior. If the learning is to transfer to life outside the prison, which is what makes this learning rehabilitative, it is crucial to make the prison opportunities and rewards similar to citizenship activities outside of prison. The inmates should be rewarded for respecting the rights, life and property of others. This would be fairly easy to do if it weren't for the obvious fact that there is confusion over what the rehabilitated prisoner should be like (Wright, 1973), and this citizenship goal never gets operationalized.

The third Type B resource constraint involves prison industry and vocational training. These opportunities for inmates took a major hit with the passage of restrictive federal laws on the transfer of inmate-made goods across state lines (Allen et al., 2013). But there has been a limited resurgence of this in the past 30 years. Several problems remain, however. The first is that prisons often depend upon donated material, and when the donations are made it is usually because the donating company is replacing the donated goods with more up-to-date equipment. There are, for example, computers in prisons that bear little resemblance to state-of-the-art computers. Obsolete or inadequate machinery, poorly organized activities, and antiquated work methods have resulted in a situation where the prison industry system is characterized by conditions remote from the real world of competitive business (Clear et al., 2012). Another problem is that prison industry jobs are highly competitive and there are few slots available (Alarid \& Reichel, 2013). Additionally, prison administrations want inmates to work as much as possible because it prevents idleness (Alarid \& Reichel, 2013; Clear et al., 2012) and it is good for environmental control. But if the prison took advantage of technological advances, employment time might be reduced.

What makes some prison vocational programs problematic are three factors which are unique to prison life. First, inmates cannot work a regular workday because the day is broken up by head counts which usually mean a return to the housing unit. Second, the low wages inmates are paid leads them to conclude that their work, especially in prison industries, is "make work" (Allen et al., 2013, p. 169) and not appreciated. About 30 years ago, it was suggested that inmates be paid the legal minimum wage (Toch, 1977) and then be charged board and room (Fox, 1983). While paying inmates the minimum wage has not materialized, there are a few places where the appropriate governmental unit is charging inmates for their stay to provide reimbursement for food, clothing and health care (Medina, 2011). This is problematic because of the third cause of the vocational failure which is that when few resources are available, inmates often have to choose, or are selected, to participate in either educational 
programs or vocational ones, but not both. In other prisons the trades are only available to those inmates who already have some experience because their skills are used to maintain the prison. In most prisons today, inmates only work two or three hours per day (Alarid \& Reichel, 2013, p. 132).

There is also a lack of appropriate educational resources in prison. The problem is that over half the adults in U.S. prisons can neither read nor write and have less than an eighth grade education (Shippen, 2008, p. 339). They need individual tutoring in basic reading, writing and arithmetic. A missing resource is the tutor. Some state prisons are working on this by finding inmates-as-tutors who can read above the seventh grade level (Shippen, 2008, p. 342). It might be less expensive for the prison if they could hire a teacher, but given the literacy level and the wide variety of levels of experience and intelligence, that might not work well.

Most, if not all, of the Type B resource constraints discussed thus far could be partly eliminated if it weren't for the shortage of rehabilitative funds. Facing budget shortfalls, some states have reduced funds for inmate services (Phelps, 2012; Scott-Hayward, 2009). Although many prisons have recently received federal aid for physical and programmatic renovations (Miller, 2014), there are many others that have not. The chances of more funds becoming more available and distributed around the states is fair. Recent court cases have opened up this possibility. What works against increased funding, however, are the conservative political climate and the notion that inmates are "lesser" people who have broken the social contract and whose living environment should be inferior, or at least no better than that of the lowest classes of the noncriminal population.

The last resource constraint to be considered here is the fact that inmates generally lack influential connections to the outside community. "Influential" refers to social contacts outside the family who can serve as a positive support network. Although this is changing due to the recent prisoner reentry movement (Miller, 2014), prisons and their inmates are largely isolated from these community sources. This is partly because the outside world is reluctant to look at the corrections field and partly because the growth in corrections as a profession has heightened its isolation. Prior to World War II there was a large number of citizens who provided supplementary or direct parole supervision (O'Leary, 1969). This group of people declined for a while during the corrections professionalization and then the numbers leveled off at relatively low levels. What is needed is a revitalization of at least three types of citizen groups who are recognized by the prison administration as supportive friends to the inmate. One group could tutor the functionally illiterate inmates or simply write to inmates. The second type of citizen role would be that of the social advocate. These people alert the public to issues and conditions within the prison and try to muster media and legislative support for the mobilization of funds and programs. The National Institute of Corrections (NIC) is a division of the Federal Bureau of Prisons and has been a strong force for prison standards and policy improvements (Clear et al., 2012). Similarly, the American Corrections Association (ACA) actively lobbies for standards and accredits prisons based on these standards (Clear et al., 2012). The last citizen role would be that of a peer culture supporter. It has been said that maintaining peer group relations is one of the most important elements tending to foster rehabilitation (Leopold, 1969). The peer supporter would be matched to the inmate by age, 
place of residence, ethnic of racial group, for example. Prisons have been criticized for ignoring the group and social context from which the inmate enters prison (Irwin, 1980). Citizen groups would address this problem. The volunteer would help the inmate through the culture shock experienced when the customary ways of coping are hopelessly challenged (Toch, 1977).

There is not much hope for the revitalization of outside citizen involvement, with the exception of large recognized groups like the NIC and ACA. To begin with, as Goffman (1961) recognized, prisons need some impermeability to maintain custodial stability. And prison administrators have been reluctant to let outsiders get involved since the reform movement of the late 1960s and early 1970s when prisoners' rights groups were very active. Since then, the courts have taken back some of the rights extended to inmates at the height of the movement. Prison administrators have responded to this trend and take a more isolationist and authoritarian stance. Another reason that citizen involvement will remain at a low ebb is that the general public is not interested in prisons any more.

\section{Discussion}

Where does this leave the future of rehabilitation? There seems to be very little hope that these internal environmental and resource constraints on the educational and medical technologies will be eliminated. The goals of prison and the resulting technologies have always been dependent upon American culture. Seiter (2014, p. 410) points out that in 2006, 87 percent of the public surveyed supported rehabilitation over a punishment-only system. While there is this renewed interest in rehabilitation, today's social and political climate only supports limited prison reform, mostly towards inmate reentry initiatives (Colgan, 2007). Unfortunately, the climate also still seems to support the internal constraints on rehabilitation. Travis (2007) believes that parole agencies resist the current national interest in reentry because they see it as a criticism of their work. This leaves the future of rehabilitation, and what to do about it, up for debate (Phelps, 2012). Today the combination of Type A (environmental) and Type B (resource) constraints to rehabilitation, and the resultant instability of rehabilitation, has led to people calling for the cojoining of rehabilitation with evidence-based programming and custody (Miller, 2014). Political, economic and social issues need to be addressed before any further public policy is changed.

Political issues involve the public's fear of crime, the legislated stiffer sentences and the "hard-on-crime" approach adopted by police, judges and prison administrators. As long as this conservative climate exists, the techniques of control and custody will prevail over the goal of rehabilitation. The economic issues include the high cost of imprisonment, overcrowding, understaffing, and the public's concern over taxation. The social issues involve the removal of the offender from his family, the lack of prison and inmate connections to the community and the eventual return of the inmate to the community where he is expected to be a participating citizen who respects the rights and property of others. As these issues get discussed and the debate goes on as what to do with prisons, the correctional profession could be thinking about how the internal constraints could be eliminated if rehabilitation ever became a more broadly accepted goal. 
By consciously eliminating the internal constraints to rehabilitation and replacing them with supporting factors, the transformational techniques could freely operate. The altered human material would find a place in communities that provide support rather than stigma. The individual would value the importance of a safe environment and his responsibility to it. His time spent in prison would teach him decency and self-worth. He would be treated like a citizen and would work and earn at a level deserving of respect. He would not be coerced into self-improvement, but would choose his own way in a supportive environment.

It should be noted that this environment would not have to be created at the expense of custody. At the beginning of this essay it was noted that transformation and custody were not coequal goals during the rehabilitation era (1930-1974). Today this is changing, but it is doubtful that the attitude inside the prison is. The human alteration that has been discussed by Goffman (1961), Perrow (1958) and Foucault (1977) as having a control function is now being mixed with the rebuilding of the individual who can "make it" honestly and successfully on the outside. As Irwin (1980:240) said 34 years ago, the inmate could pay the price for his crime and be punished without being depowered and debased. The transformation can be done without treatment and custody being incompatible. If reduced recidivism rates are the evaluative criteria, then the current high recidivism rates indicate that rehabilitation might not be effective, and critics are right in saying it has only a limited successful future in its present restrictive environment. With more political and cultural change, however, it could work.

\section{Conclusion}

What has been argued in this essay is that rehabilitation as a transformational modality, takes the form of two technologies; education (in the broad sense) and the medical model. It has been shown that each of these technologies has a set of techniques through which the technologies get applied to human material, prison inmates, in an effort to change and alter these inmates so that they can return to society and participate in social institutions, the labor force, neighborhoods and schools, and will respect the rights and property of others. It has also been argued that prisons during the rehabilitation era only had limited success in their attempts to make this transformation work, and the major goal of this essay was to explain why prisons continue to struggle in this regard.

To this end, two types of internal constraints on the rehabilitative technologies and their techniques have been identified; (1) Type A (Environmental Constraints) which are attitudes, conditions, values and communication skills which determine the prison environment and the situational reality and (2) Type B (Resource Constraints) which are the lack of technological materials, rehabilitative opportunities, and catalysts which are needed to make the transformational process happen. Some insight was provided as to the internal and external causes of these constraints, and it was explained how these constraints worked against the rehabilitative efforts. Also offered were some estimates as to the chances of reducing or eliminating these constraints.

The concrete improvements that need to continue to increase the probability of rehabilitation include: (1) keeping the prison environment safe and clean, (2) constructing smaller prisons, 
(3) treating the inmates with dignity and respect, (4) upgrading the penal administration financially and socially, to attract qualified professionals, (5) encouraging and increasing outside contacts for inmates, (6) making prison work meaningful and providing modern methods, (7) offering more voluntary opportunities for self-improvement and self-government, (8) increasing psychological diagnosis, individual and group therapy, (9) continue instituting determinate or "fixed" sentences and not returning to the indeterminate sentence, and (10) making available more relevant educational resources and opportunities. As these improvements continue, rehabilitation has to return as a major goal and be operationally defined and understood.

Finally, while the vast majority of Americans favor rehabilitation over a punitive-only penal policy, the return of rehabilitation as a full-blown major goal is not likely to happen. The political climate in the United States today is against its return and, as Perrow (1958) and Goffman (1961) have each stated, the climate inside the institution reflects that on the outside. Yet, it can no longer be claimed that nothing works. There is scientific evidence that some things do work to reduce recidivism and prepare inmates for their eventual return to the community if they are based on cognitive-behavioral techniques, are carefully matched to individual inmate needs, and lead towards the development of life skills.

Can these conclusions about the environmental and resource constraints on transformational technologies in American prisons be generalized to prison systems outside the United States? Only in the broad sense that other countries also have constraints on their transformational technologies. Those were not studied here, but it would be a valuable scholarly pursuit. There would be many variations in the form and strength of those constraints and in the causes of them. Countries have unique criminal justice systems because they have different political and socio/economic systems, histories and cultures. There are differences in crimes, educational and medical technologies, and resources. And what do the countries have as their primary penal philosophy? Is it incapacitation, deterrence, restoration, retribution or rehabilitation? Or is it a combination of these? What does their public value and believe? What seems clear is that whenever there are competing ideologies there will also be constraints on the different goals and means to obtain them, especially when one goal is subordinate to another.

\section{Acknowledgements}

The author wants to thank undergraduate students Courtney A. Carton, Alyssa K. Dolson and Colleen D. Doucette, and the Social and Behavioral Sciences Administrative Assistant, Sharon L. MacCartney, for their assistance.

\section{References}

Allen, H. E., Friday, P. C. Roebuck, J. B., \& Sagarin, E. (1981). Crime and punishment. New York: The Free Press.

Allen, H. E., Latessa, E. J., \& Ponder, B. S. (2013). Corrections in America: An introduction (13th ed.). Upper Saddle River, NJ: Pearson Education. 
Allen, H. E., Latessa, E. J., Ponder, B. S., \& Simonsen, C. E. (2007). Corrections in America: An introduction. Upper Saddle River, NJ: Pearson Education.

Alarid, L. F. \& Reichel, P. L. (2013). Corrections. Upper Saddle River, NJ: Pearson Education.

Aos, S., Miller, M. \& Drake, E. (2006). Evidence-based adult correctional programs: What works and what does not. Olympia: Washington State Institute for Public Policy.

Bailey, W. C. (1966). Correctional outcome: An evaluation of 100 reports! Journal of Criminal Law, Criminology and Political Science, 57, 153-60. http://dx.doi.org/10.2307/1141289

Batiuk, M. E., Lahm, K. F., McKeever, M., Wilcox, N., \& Wilcox, P. (2005). Disentangling the effects of correctional education: Are current policies misguided? - An event history analysis. Criminal Justice, 5(1), 55-74.

Baunach, P. J. (1981). Participatory management: Restructuring the prison environment. In D. Fogel \& J. Hudson (Eds.), Justice as fairness: Perspectives on the justice model (pp. 196-218). New York: Anderson Publishing Co.

Bentham, J. (1962). Works. Vol. I. New York: Russell and Russell.

Bohm, R. M. (2006). "McJustice": On the McDonaldization of criminal justice. Justice Quarterly, 23(1), 127-145. http://dx.doi.org/10.1080/07418820600552576

Clear, T. R., Cole, G. F., Reisig, M. D., \& Petrosino, C. (2012). American corrections in brief. Belmont, CA: Wadsworth, Cengage Learning.

Colgan, B. A. (2007). The presidential politics of prisoner reentry reform. Federal Sentencing Reporter, 20(2), 110-123. http://dx.doi.org/10.1525/fsr.2007.20.2.110

Conrad, J. P. (1981). Where there's hope there's life. In D. Fogel \& J. Hudson (Eds.), Justice as fairness: Perspectives on the justice model (pp. 3-21). New York: Anderson Publishing Co.

Cressey, D. R. (1975). Limitations on organization of treatment in the modern prison. In Theoretical studies in social organization of the prison (pp. 62-84). Millwood, New York: Kraus Reprint Co.

Cullen, F. T. (2005). The twelve people who saved rehabilitation: How the science of criminology made a difference. Criminology, 43(1), 1-42. http://dx.doi.org/10.1111/j.0011-1348.2005.00001.x

Cullen, F. T., \& Jonson, C. L. (2012). Correctional theory: context and consequences. Thousand Oaks, CA: SAGE Publications.

DeLisi, M., \& Conis, P. J. (2013). American corrections: Theory, research, policy, and practice,(2nd ed.) Burlington, MA: Jones \& Bartlett Learning.

Farmer, J. F. (2012). Testing the conceptual path to correctional staff safety: A study of the implementation of unit management in two medium scurity state institutions in the USA. 
International Journal of Criminal Justice Sciences, 7(1), 431-448.

Fogel, D., \& Hudson, J. (1981). (Eds.) Justice as fairness: Perspectives on the justice model. New York: Anderson Publishing Co.

Foucault, M. (1977). Discipline and punish: The birth of the prison. Translated by A. Sheridan. New York: Pantheon Books.

Fox, V. (1983). Correctional institutions. Englewood Cliffs, NJ: Prentice-Hall Inc.

Frampton, M. L., Lopez, I., \& Simon, J. (Eds.). After the War on Crime: Race, Democracy, and a New Reconstruction. New York: New York University Press.

Garland, D. (2001). The culture of control: Crime and social order in contemporary society. Chicago: University of Chicago Press.

Goffman, E. (1961). Asylums: Essays on the social situation of mental patients and other inmates. Garden City, NY: Anchor Books.

Goodman, P. (2012). "Another second chance": Rethinking rehabilitation through the lens of California's prison fire camps. Social Problems, 59(4), 437-458. http://dx.doi.org/10.1525/sp.2012.59.4.437

Grusky, O., \& Miller, G. (1970). The sociology of organizations. New York: The Free Press.

Hawkins, G. (1976). The prison; Policy and practice. Chicago: The University of Chicago Press.

Irwin, J. (2005). The warehouse prison: Disposal of the new dangerous class. Los Angeles: Roxbury Publishing Co.

Irwin, J. (1980). Prisons in turmoil. Boston: Little, Brown and Co.

Jayewardene, C. H. S., \& Jaysuriya, D. J. N. (1981). The management of correctional institutions. Toronto: Butterworth and Company.

Johnson, E. H. (1972). Prison industry. In R. M. Carter, D. Glaser \& L. T. Wilkins. (Eds.), Correctional institutions (2nd ed.). Philadelphia: J.B. Lippincott Co.

Lageson, S. (2014). Correcting American Corrections, with Francis Cullen, David Garland, David Jacobs, and Jeremy Travis. In D. Hartmann \& C. Uggen (Eds.), Crime and the punished (pp. 141-154). New York: W.W. Norton \& Company, Inc.

Lambert, E., Hogan, N., Barton, S. M., Jiang, S., \& Baker, D. N. (2008). The impact of punishment and rehabilitation views on organizational commitment among correctional staff: A preliminary study. American Journal of Criminal Justice, 33, 85-98. http://dx.doi.org/10.1007/s12103-007-9026-7

Leopold, N. (1960). What is wrong with the prison system. In H. Periman \& T. Allington (Eds.), The tasks of penology (pp. 21-46). Lincoln: University of Nebraska Press.

Martinson, R. (1974). What works? Questions and answers about prison reform. Public 
Interest, Spring, 22-55.

Medina, J. (2011). In California, a plan to charge inmates for their stay. The New York Times, December 12, A15.

Melossi, D. \& Pavarini, M. (1981). The Prison and the factory; Origins of the penitentiary system. London: The Macmillan Press, LTD.

Miller, J. M. (2014). Identifying collateral effects of offender reentry programming through evaluative fieldwork. American Journal of Criminal Justice, 39, 41-58. http://dx.doi.org/10.1007/s12103-013-9206-6

O'Leary, V. (1969). Some directions for citizen involvement in corrections. The Annals of the American Academy of Political and Social Science, 381, 99-108. http://dx.doi.org/10.1177/000271626938100112

Perrow, C. (1958). Hospitals: Technology, structure and goals. In J. March \& H. Simon, (Eds.), Organizations (pp. 910-966). New York: Wiley.

Petersilia, J. (2011). Beyond the bubble. NIJ Journal, 268, 26-31.

Pfeffer, J. (1981). Power in organizations. Marshfield, MA: Pitman Publishing, Inc.

Phelps, M. S. (2011). Rehabilitation in the punitive era: the gap between rhetoric and reality in U.S. prison programs. Law \& Society Review, 45, 33-67. http://dx.doi.org/10.1111/j.1540-5893.2011.00427.x

Phelps, M. S. (2012). The place of punishment: Variation in the provision of inmate services staff across the punitive turn. Journal of Criminal Justice, 40(2012), 348-357. http://dx.doi.org/10.1016/j.jcrimjus.2012.06.012

Prettyman, Jr., \& Barrett, E. (1981). The indeterminate sentence and the right to treatment. In D. Fogel \& J. Hudson, (Eds.), Justice as fairness: Perspectives on the justice model (pp. 71-89). New York: Anderson Publishing Co.

Rossum, R. A., \& Rossum, C. (2014). Rehabititating rehabilitation. The World and I, 18(12), 24-29.

Skarbek, D. B. (2010). Self-governance in San Pedro Prison. The Independent Review, 14(4), 569-585.

Seiter, R. P. (2014). Corrections: An introduction (4th ed.) Upper Saddle River, NJ: Pearson Education.

Serrill, M. S. (1975). Is rehabilitation dead? Corrections Magazine, May-June, 5-25.

Shannon, S. \& Uggen, C. (2014). Visualizing punishment. In D. Hartmann \& C. Uggen, (Eds.),_Crime and the Punished (pp. 42-62). New York: W.W. Norton \& Company, Inc.

Shippen, M. E. (2008). A pilot study of the efficacy of two adult basic literacy programs for incarcerated males. The Journal of Correctional Education, 59(4), 339-347. 


\section{Macrothink}

Journal of Social Science Studies

ISSN 2329-9150

2014, Vol. 1, No. 2

Simon, J. (2013). The return of the medical model: Disease and the meaning of imprisonment from John Howard to Brown v. Plat. In Harvard Civil Rights-Civil Liberties Law Review, 48 (pp. 217-256).

Smart, B. (1985). Michel Foucault. London: Tavistock Publications. http://dx.doi.org/10.4324/9780203405741

Steen, S., \& Bandy, R. (2007). When the policy becomes the problem: Criminal justice in the new millennium. Punishment \& Society, 9(1), 5-26. http://dx.doi.org/10.1177/1462474507070548

Stinchcomb, J. B. (2011). Corrections: Foundations for the future (2nd ed.). New York: Routledge.

Street, D. (1970). The inmate group in custodial and treatment settings. In O. Grusky \& G. A. Miller, (Eds.), The sociology of organizations: Basic studies. New York: The Free Press.

Toch, H. (1977). Living in prison; The ecology of survival. New York: The Free Press.

Travis, T. (2007). Reflections on the reentry movement. Federal Sentencing Reporter, 20(2), 84-87. http://dx.doi.org/10.1525/fsr.2007.20.2.84

Wacquant, L. (2008). The place of the prison in the new government of poverty. In M. Frampton, I. Lopez, \& J. Simon, (Eds.), After the war on crime: Race, democracy, and a new reconstruction (pp. 23-36). New York: New York Univ. Press.

Wilkins, L. T. (1969). Evaluation of penal measures. Berkeley and Los Angeles: University of California Press.

Wright, E. O. (1973). The politics of punishment: New York: Harper Row.

\section{Copyright Disclaimer}

Copyright reserved by the author(s).

This article is an open-access article distributed under the terms and conditions of the Creative Commons Attribution license (http://creativecommons.org/licenses/by/3.0/). 